\title{
Comparative Analysis of Comfort Properties of Bio- Mimetic Branching Structured Plant Fabrics with Commercial Fabrics
}

\author{
Sarkar Manas Kumar ${ }^{1 *}$, Chen Qing ${ }^{2}$ and Fan Jintu ${ }^{1 *}$ \\ ${ }^{1}$ Institute of Textiles and Clothing, Hong Kong Polytechnic University, Hong Kong \\ ${ }^{2}$ Shanghai International Fashion Innovation Center, Donghua University, China
}

*Corresponding author: Prof Fan Jintu and Dr. Sarkar Manas Kumar, Institute of

Textiles and Clothing, Hong Kong Polytechnic University, Hong Kong.

Received Date: December 23, 2020

Published Date: January 08, 2021

\begin{abstract}
In this research, comfort property, in terms of water absorption and breathability, of noble two and three-layered branching plant structured fabrics of different weights were compared with existing market fabric samples. Besides, a simple model was derived to understand the water flow through the branching structured fabrics against a regular parallel structured one. The model suggests that branching structured materials can faster transport water against the parallel one. Experimental results suggested that branching structured plant fabrics have immense advantages in terms of instant absorption, vertical wicking, in-plane spreading, and breathability of similar weighted market fabrics. The research proved that these branching structured plant fabrics have a lot of potentials to be used as lightweight dress materials for the summer.
\end{abstract}

Keywords: Branching structured fabric; Biomimetic; Absorption; Wicking; Breathability

\section{Introduction}

Clothing comfort is considered as one of the key properties desired by a consumer of appeal products. The main properties that dictated clothing comfort are absorption and breathability of the materials [1]. To stay cool on a hot summer day, super absorbing and highly breathable fabrics are recommended [2].

Nature shows many branching structures, such as river basins [3], trees, or plants [4], which are naturally created to improve water management. In our earlier research, imitating the branching structure of a plant, we developed the noble biomimetic triplelayered [5] and double-layered [6] branching structured plant fabrics with faster water absorption properties. A triple-layered fabric (Figure 1(a)) consist of three integrated layers, the bottom layer is of 4/4 matt structure, in which four yarns are grouped together to form a main "stem". The "four-yarn stem" is then split into two "two-yarn branches" in the middle layer, which is achieved by $2 / 2$ matt weave. The top layer is a plain weave, in which the yarns are separate so as to have a greater surface area to volume ratio. To reduce the weight of this noble triple layered fabric, a double layered branching structured plant fabric was created(Figure 1(b)), in this structure, the entire bottom layer of the triple layered design was removed. Here two yarns in the bottom-layer of the fabric are grouped together using a design like 2/2 Matt and split into individual yarns by using plain design in the face of the fabric.

From our previous researches [5-7], it is clear that the novel branching structured plant fabrics have better absorption properties as compared to other interchanging weave structures produced in our weaving laboratory. This is not enough to convince the manufacturers to adapt the novel branching structured plant design for better comfort. It is thus necessary to compare the plant structured fabrics against common single layer fabrics as well as other moisture management fabrics available in the market. 
In this research, we compare different branching structured plant fabrics against common single layer fabrics as well as other moisture management fabrics available in the market. For this purpose, a total of eight lightweight plant structured fabric samples of varying constructions were compared against some fabric samples available in the market to judge the quality of the plant structured fabrics against the best quality moisture management fabrics in the market. In addition, a simple model was derived to understand the advantages of branching structures against the regular structures of the fabric.

\section{Experimental}

\section{Fabrics}

Imitating the branching structure of a plant, as shown in Figure 1(a) and (b), we developed a total of eight lightweight branching structured plant fabrics and one interchanging plain fabric as per the method described in our previous research papers[6, 7]. Out of these eight branching structured fabrics, one was three-layered branching structured, and the rest seven fabrics were two-layered branching structured fabrics. After weaving, all fabrics were scoured and bleached using the standard scouring and bleaching recipe.

Five commercial fabric samples were considered, which included two woven fabrics and three knitted fabrics, for comparison with these plant fabrics. One of the two woven fabrics was a plain single layer fabric and the other was a twill fabric. Three knitted fabrics included the commercial "Dryfit" fabric, a commercial fabric with absorption finish collected from the local market, and a "Dry Release" fabric. Detailed constructions of all fabrics are presented in Table1. The weight and thickness of the branching structured fabrics were maintained within a similar range of the available commercial fabric samples for better comparison.

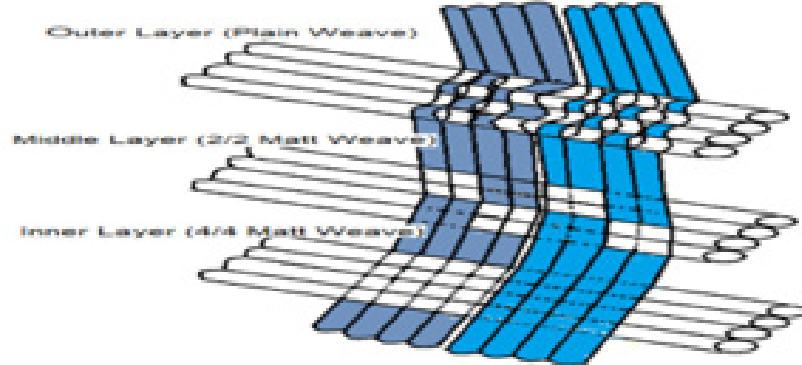

(a)

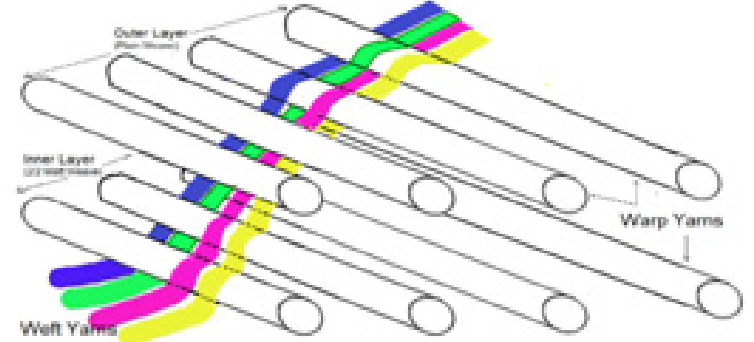

(b)

Figure 1: Branching structured Plant fabric (a) Three layers (b) Two layers.

\begin{tabular}{|c|c|c|c|c|c|c|c|}
\hline Sr. no. & $\begin{array}{l}\text { Fabric Design and construc- } \\
\text { tion }\end{array}$ & Warp Yarn & Weft Yarn & Weight & Thickness & Ends/Cm & Picks/Cm \\
\hline & & & & $\mathrm{g} / \mathrm{mt}^{2}$ & $\left(\mathrm{x} 10^{-3} \mathrm{mt}\right)$ & & \\
\hline \multicolumn{8}{|c|}{ Three-layer Plant-structure Fabrics } \\
\hline 1 & $\begin{array}{c}\text { Three-layer Plant-struc- } \\
\text { ture(F*-plain, M-2/2 Matt, } \\
\text { B-4/4 Matt) }\end{array}$ & $\begin{array}{l}11.11 \text { Tex poly- } \\
\text { ester }\end{array}$ & 7.38 Tex Cotton & 190.9 & 0.72 & 68 & 125 \\
\hline 2 & $\begin{array}{l}\text { Three-layer interchanged } \\
\text { Plain(F-Plain, M-Plain, } \\
\text { B-plain) }\end{array}$ & $\begin{array}{l}11.11 \text { Tex poly- } \\
\text { ester }\end{array}$ & $\begin{array}{l}\text { 7.38 Tex Cotton } \\
\text { Yarn }\end{array}$ & 190.9 & 0.71 & 68 & 125 \\
\hline \multicolumn{8}{|c|}{ Two-layer Plant-Structured fabrics of different weight } \\
\hline 3 & $\begin{array}{c}\text { Plant structure (F-Plain, } \\
\text { B-2/2 Matt) }\end{array}$ & $\begin{array}{l}11.11 \text { Tex poly- } \\
\text { ester }\end{array}$ & 7.38 Tex Cotton & 168.7 & 0.56 & 64 & 86 \\
\hline 4 & $\begin{array}{c}\text { Plant structure (F-Plain, } \\
\text { B-2/2 Matt) }\end{array}$ & $\begin{array}{l}11.11 \text { Tex poly- } \\
\text { ester }\end{array}$ & 19.76tex Coolmax & 226.5 & 0.67 & 65 & 64 \\
\hline 5 & Plant Structure & 9.85 Tex Cotton & 7.38 Tex Cotton & 139.6 & 0.59 & 75 & 78 \\
\hline 6 & Plant Structure & 9.85 Tex Cotton & 7.38 Tex Cotton & 129.4 & 0.59 & 73 & 72 \\
\hline 7 & Plant Structure & 9.85 Tex Cotton & 7.38 Tex Cotton & 125.2 & 0.57 & 72 & 69 \\
\hline 8 & Plant Structure & 9.85 Tex Cotton & 7.38 Tex Cotton & 116.1 & 0.56 & 70 & 61 \\
\hline 9 & Plant Structure & 9.85 Tex Cotton & 7.38 Tex Cotton & 112.9 & 0.57 & 70 & 56 \\
\hline
\end{tabular}




\begin{tabular}{|c|c|c|c|c|c|c|c|}
\hline \multicolumn{8}{|c|}{ Market Samples } \\
\hline \multicolumn{8}{|c|}{ Woven } \\
\hline 10 & Twill high absorbing fabric & 30 Tex Cotton & 36 Tex Cotton & 240.24 & 0.54 & 36 & 23 \\
\hline 11 & Plain $100 \%$ cotton fabric & 14.76 Tex warp & 14.76 Tex weft & 121 & 0.37 & 53 & 29 \\
\hline \multicolumn{8}{|c|}{ Knitted } \\
\hline 12 & $\begin{array}{l}\text { Blue-knit(absorption finish) } \\
\text { (Single jersey weft knitted) }\end{array}$ & \multicolumn{2}{|c|}{$100 \%$ Polyester $15.01 \mathrm{Tex}$} & 204.32 & 0.59 & 19 & 18 \\
\hline 13 & $\begin{array}{c}\text { Dry-Fit (Double jersey } \\
\text { warp Knitted fabric special } \\
\text { finished) }\end{array}$ & \multicolumn{2}{|c|}{ 100\% Cotton $12.43 \mathrm{Tex}$} & 206.18 & 0.93 & 24 & 22 \\
\hline 14 & $\begin{array}{l}\text { Dry release (special finished } \\
\text { weft knitted) }\end{array}$ & \multicolumn{2}{|c|}{$100 \%$ cotton $14.82 \mathrm{Tex}$} & 198.2 & 0.54 & 18 & 18 \\
\hline
\end{tabular}

Note: *F-Face fabric; M- Middle fabric; B-Back fabric

\section{Testing}

Absorption property and air-permeability of all branchedstructure fabrics samples and commercial fabric samples were tested. For absorption property, all fabrics were tested for vertical wicking test(DIN53924), drop test( AATCC 79). For the vertical wicking test, the fabric strips were taken 1 " wide and 15" long and hanged vertically from a clamp in such a way that the lower 1.8" of the sample was immersed in the water. The vertical wicking height was recorded after 30 minutes for each sample. During the drop test, the samples were mounted in an embroidery frame in such a way that the inner side (which touches the skin) faces upwards. An amount of $0.2 \mathrm{ml}$ water was dropped by a burette on the fabric from a distance of $2 \mathrm{~cm}$ above the fabric samples. The area of spreading on the fabric surface was measured after two minutes.

The initial absorption rate of all fabrics was tested on the Transplanar Water Transport Tester (TWTT) [8], which measures the absorption of fabrics in a realistic profusely sweating condition. Also, the air permeability (ASTM-D737-04) of all fabric samples was tested on the Shirley air permeability tester. Before testing all fabric samples were conditioned for 24 hours in a standard testing condition.

\section{Results and Discussion}

\section{Vertical wicking}

The vertical wicking results of all fabric samples are presented in Table 2. The values are the vertical wicking height of different fabrics after 30 mins. The vertical wicking results of different Table 2: Result of vertical wicking test. branching structured fabrics are generally higher as compared to the market samples. Among the market samples, knitted fabrics showed a better vertical wicking property against the woven ones. All plant fabrics exhibited faster wicking property against the standard woven fabrics collected from the market. In addition, all $100 \%$ cotton branching structured plant fabrics have superior wicking property against all the market samples. When $100 \%$ cotton plant structured fabric (Sample no 7 with $125.2 \mathrm{~g} / \mathrm{m} 2 \mathrm{wt}$ ) is compared with $100 \%$ plain cotton fabric (Sample no. 11 with $121.00 \mathrm{~g} / \mathrm{m} 2 \mathrm{wt}$ ), a significant $67.55 \%$ benefit was observed for the former one.

\section{Drop test}

Drop test results of eight plant structured fabrics, interchanging plain fabric, and five commercial fabrics are listed in Table 3. The values are the area of spreading of $0.2 \mathrm{ml}$ water drop on the fabric surface after two minutes. Among the commercial samples, plain cotton fabric (sample no. 11) showed wider spreading of water, and it is similar to the plant-structure fabric (sample number.3) with polyester warp and cotton weft. Although slightly heavier (139.6 $\mathrm{g} / \mathrm{m}^{2}$ and $129 \mathrm{~g} / \mathrm{m}^{2}$ ) 100\% cotton branched-structured fabrics exhibited a lesser area against the commercial plain fabric, but similar or greater wetting areas were observed in the lighter plant structured fabrics (sample no 7, 8 \& 9), which have the similar weight as that of the commercial plain one. In general, at a higher thickness, lower spreading was observed. This is probably due to the fact that thicker fabrics have more air-spaces and absorbing fibers in the unit area for absorbing liquid water.

\begin{tabular}{|c|c|c|c|}
\hline & Vertical Wicking Test (in cm) & Warp & Weft \\
\hline Sample no. & Fabric Type & 15.74 & 19.31 \\
\hline 1 & 3-layer- branching structured plant fabric & 14.21 & 17.26 \\
\hline 2 & 3-layer- interchanging plain fabric & 15.75 & 19.05 \\
\hline 3 & Two-layer-plant-polyester/Cotton & 15.75 & 20.32 \\
\hline 4 & Two-layer-plant-polyester/Coolmax & 18.54 & 16.26 \\
\hline 5 & 2-layer-plant-100\% cotton $\left(139.6 \mathrm{~g} / \mathrm{m}^{2}\right)$ & 18.54 & 16.76 \\
\hline 6 & 2-layer-plant-100\% cotton $\left(129.4 \mathrm{~g} / \mathrm{m}^{2}\right)$ & & \\
\hline
\end{tabular}




\begin{tabular}{|c|c|c|c|}
\hline 7 & 2-layer-plant-100\% cotton $\left(125.2 \mathrm{~g} / \mathrm{m}^{2}\right)$ & 21.08 & 18.29 \\
\hline 8 & 2-layer-plant-100\% cotton $\left(116.4 \mathrm{~g} / \mathrm{m}^{2}\right)$ & 21.59 & 18.8 \\
\hline 9 & 2-layer-plant-100\% cotton $\left(112.9 \mathrm{~g} / \mathrm{m}^{2}\right)$ & 13.16 & 19.56 \\
\hline 10 & Market Samples & 12.19 & 11.18 \\
\hline 11 & $100 \%$ Cotton twill & 15.75 & 12.95 \\
\hline 12 & $100 \%$ Cotton plain & 15.74 & 12.7 \\
\hline 13 & Blue-knit(absorption finish) & 16.51 & 15.24 \\
\hline 14 & Dry-fit (warp-way) & dry-release (black) & \\
\hline
\end{tabular}

Table 3: Result of drop test.

\begin{tabular}{|c|c|c|c|}
\hline Sample no. & Fabric description & Back wet-area $\left(\mathrm{cm}^{2}\right)$ & Face wet-area $\left(\mathrm{cm}^{2}\right)$ \\
\hline & Plant-structured fabric & & \\
\hline 1 & Three-layer-branched structured Plant fabric & 25.35 & 25.35 \\
\hline 2 & 3-layer- interchanging plain fabric & 24.89 & 24.89 \\
\hline 3 & Two-layer-plant-polyester/Cotton & 31.48 & 31.48 \\
\hline 4 & Two-layer-plant-polyester/Coolmax & 25.55 & 29.4 \\
\hline 5 & 2-layer-plant- $100 \%$ cotton $\left(139.6 \mathrm{~g} / \mathrm{m}^{2}\right)$ & 27.88 & 27.88 \\
\hline 6 & 2-layer-plant-100\% cotton $\left(129.4 \mathrm{~g} / \mathrm{m}^{2}\right)$ & 29 & 29 \\
\hline 7 & 2-layer-plant- $100 \%$ cotton $\left(125.2 \mathrm{~g} / \mathrm{m}^{2}\right)$ & 31.63 & 31.63 \\
\hline 8 & 2-layer-plant-100\% cotton $\left(116.4 \mathrm{~g} / \mathrm{m}^{2}\right)$ & 31.23 & 31.23 \\
\hline 9 & 2-layer-plant- $100 \%$ cotton $\left(112.9 \mathrm{~g} / \mathrm{m}^{2}\right)$ & 34.57 & 34.57 \\
\hline \multicolumn{4}{|c|}{ Market samples } \\
\hline 10 & Cotton twill & 18.96 & 18.96 \\
\hline 11 & Cotton Plain & 31.48 & 31.48 \\
\hline 12 & Blue-knit(absorption finish) & 22.81 & 22.81 \\
\hline 13 & Dry-fit & 12.77 & 13.48 \\
\hline 14 & dry-release (black) & 27.88 & 27.88 \\
\hline
\end{tabular}

\section{TWTT Test}

The initial absorption values of different plant structured fabrics are shown in Table 4. The initial absorption value of different branching structured plant fabrics indicated that thicker fabrics absorb faster (3-layers fabric absorbs faster than 2-layers). All plant structured fabrics absorb faster than the woven fabrics collected from the market. The results indicate that the knitted samples from the market with hydrophilic finishes had better initial absorption property, but the absorption property drastically reduced after 10 minutes of boiling wash with $1 \%$ soda ash and $1 \%$ soap solution. After washing, the absorption property of most of these knitted market fabrics becomes slower than the three and two-layer plant structured fabrics. This means the absorption property of chemically finished moisture management fabrics are not durable, whereas the absorption properties of plant-structured fabrics are permanent as no chemical finishes are involved.

Table 4: Air-permeability of various fabrics.

\begin{tabular}{|c|c|c|}
\hline Sample No. & Sample description & Air-permeability $\left(\mathbf{m l} / \mathbf{s e c} / \mathbf{c m}^{2}\right)$ \\
\hline 1 & Branching structured plant fabric & 27.6 \\
\hline 2 & 3-layer branching structured plant fabric & 24.7 \\
\hline 2 & 3-layer- interchanging plain fabric & 41.3 \\
\hline 3 & 2-layer Plant $p /$ cot & 32.5 \\
\hline 4 & 2-layer Plant $p /$ coolmax & 31.5 \\
\hline 5 & 2-layer-plant-100\% cotton $\left(139.6 \mathrm{~g} / \mathrm{m}^{2}\right)$ & 35.4 \\
\hline 6 & 2-layer-plant-100\% cotton $\left(129.4 \mathrm{~g} / \mathrm{m}^{2}\right)$ & 38.4 \\
\hline
\end{tabular}




\begin{tabular}{|c|c|c|}
\hline 7 & 2-layer-plant- $100 \%$ cotton $\left(116.4 \mathrm{~g} / \mathrm{m}^{2}\right)$ & 45.3 \\
\hline 8 & 2-layer-plant-100\% cotton $\left(112.9 \mathrm{~g} / \mathrm{m}^{2}\right)$ & 53.1 \\
\hline Market samples & & 4.3 \\
\hline 9 & Cotton Twill fabric & 11.8 \\
\hline 10 & Cotton Plain Fabric & 60 \\
\hline 11 & Blue-knit(absorption finish) & 78.7 \\
\hline 12 & Dry-fit & 62 \\
\hline 13 & Dry-release(Absorption finish) & \\
\hline
\end{tabular}

Table 5: Initial absorption result on TWTT for all fabrics.

\begin{tabular}{|c|c|c|c|}
\hline Sample no. & Fabric Type & Initial Absorption & CV\% \\
\hline \multicolumn{4}{|c|}{ Plant-Structured Fabrics } \\
\hline 1 & 3-layer-branching structured-Plant fabric & 2.32 & 2.35 \\
\hline 2 & 3-layer- interchanging plain fabric & 2.01 & 2.23 \\
\hline 3 & Two-layer-plant-polyester/Cotton & 1.9 & 2.32 \\
\hline 4 & Two-layer-plant-polyester/Coolmax & 1.72 & 2.14 \\
\hline 5 & 2-layer-plant- $100 \%$ cotton $\left(139.6 \mathrm{~g} / \mathrm{m}^{2}\right)$ & 1.8 & 2.11 \\
\hline 6 & 2-layer-plant- $100 \%$ cotton $\left(129.4 \mathrm{~g} / \mathrm{m}^{2}\right)$ & 1.82 & 2.06 \\
\hline 7 & 2-layer-plant- $100 \%$ cotton $\left(125.2 \mathrm{~g} / \mathrm{m}^{2}\right)$ & 1.84 & 2.86 \\
\hline 8 & 2-layer-plant- $100 \%$ cotton $\left(116.4 \mathrm{~g} / \mathrm{m}^{2}\right)$ & 1.9 & 3.41 \\
\hline 9 & 2-layer-plant-100\% cotton $\left(112.9 \mathrm{~g} / \mathrm{m}^{2}\right)$ & 1.66 & 3.87 \\
\hline \multicolumn{4}{|c|}{ Market Samples } \\
\hline 10 & $100 \%$ Cotton twill & 1.44 & 3.41 \\
\hline 11 & $100 \%$ Cotton plain & 1.48 & 2.27 \\
\hline 12 & Blue-knit(absorption finish) & 2.22 & 2.29 \\
\hline $12 \mathrm{a}$ & Sample No. 11 after soap and soda wash & 1.68 & 2.87 \\
\hline 13 & Dry-fit & 1.8 & 3.54 \\
\hline 14 & Dry-release (black) & 1.7 & 2.44 \\
\hline
\end{tabular}

\section{Air-permeability}

The air-permeability value indicates the amount of air that can pass through various fabrics (Table 5). In general, results indicate that the air permeability of the knitted fabrics is better than those of the woven ones. Among the woven fabrics, plant structured fabrics showed greater air permeability. The commercial $100 \%$ cotton single-layer plain and twill woven fabrics, which are commonly used as shirting fabric, has a substantially lower air permeability value compared with the plant-structure fabrics of similar weight. This is possibly due to the fact that in the branching structured fabrics, yarns are arranged in layers, which increases the air gaps in the fabric.

\section{Modeling}

A simple model was established to compare liquid movement in a branching structured plant fabric with interchanging plain fabrics. The diameter of the structure reduces from bottom to the top as exists in the plant structured fabric observed from the microscopic view [6]. The dimension of the structure was decided in the proportion of the imaginary holes of the plant (which was decided in proportion to the diameter of yarns). The main purpose of this model is to examine the effect of the branching structure on the liquid flow rate in comparison with a non-branching structure. The dimension (Figure 2 ) of the branching structure is based on the three-layered branching structure plant fabric. The entire thickness of the branching structured plant fabric is considered as consisting of thicknesses of three layers of the fabric (i.e $0.28+0.23+0.21=$ $0.72 \mathrm{~mm}$ ). The proportion of the thickness of the different layers of the branching is determined on the basis of the ratio of the thickness of 4/4-Matt structure over 2/2 Matt structure and plain structure from the same yarn. The angle of deflection for the branches was considered as $60{ }^{\circ} \mathrm{c}$ and $30{ }^{\circ} \mathrm{c}$ to maintain a uniform structure of a plant.

\section{Model details}

Initially, the three-dimension branching structure of the plant was designed using software 'Solidworks', which is very much efficient for the 3-D geometry. The output file of the Solidworks is 'plant.iges' (i.e. with 'iges' extension), which is the input file for the Gambit software. In this plant structure model (Fig 3), ' $\mathrm{A}$ ' is the inlet, 
indicates the main stem, and all 'B's are the outlets, as final subbranches, of the plant. Fig. illustrates the solid picture of the same plant-structure model.

The plant structure is compared with a model of four parallel pipes (depicted in Figure 3), each having a diameter of $0.1 \mathrm{~mm}$ (i.e. equal to the diameter of the 2 nd branch of the plant-structure) and a length which is the same as the total passage length of the plant structure. The cross-sectional area of the inlets ('A') and outlets (' $\mathrm{B}$ ') of the four parallel pipes model is the same. From the Gambit, a 'mes' file was obtained for the model.

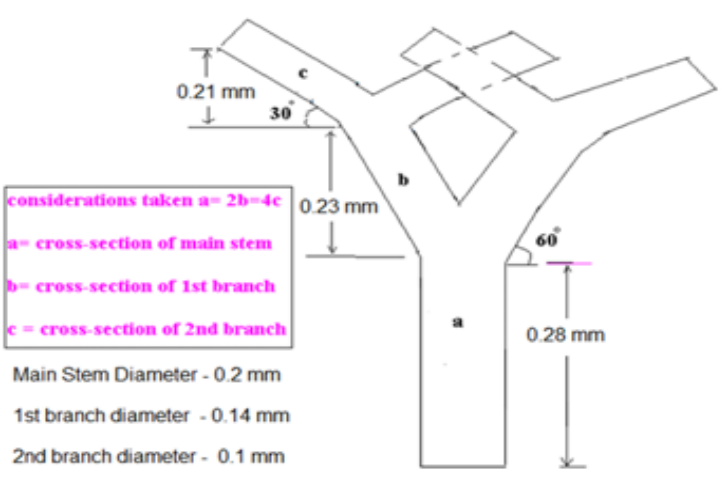

Figure 2: Dimension of the model branching structured plant fabric.
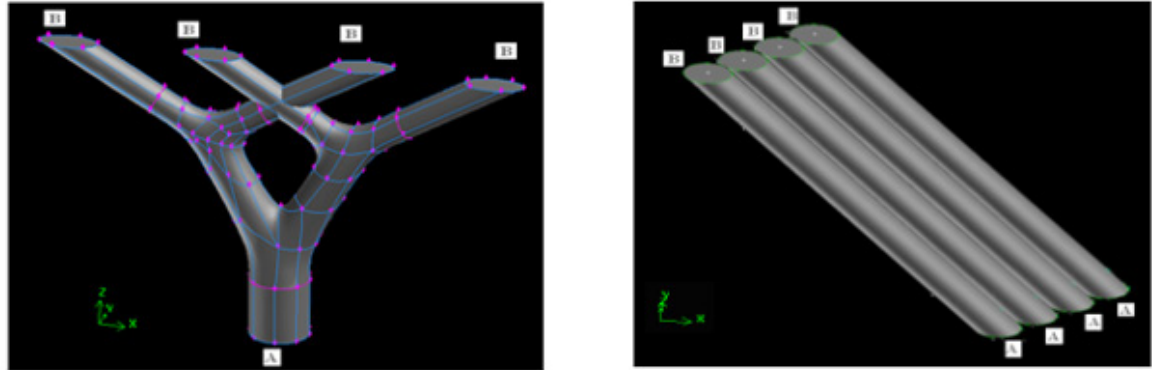

Figure 3: Picture of the plant-structure and parallel structure in Gambit software.

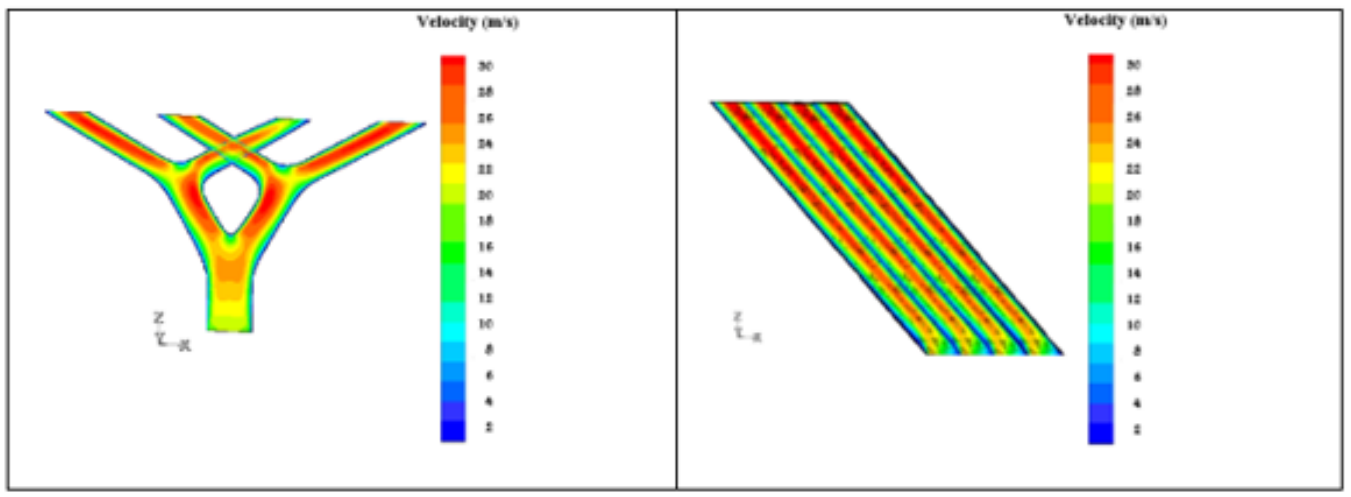

Figure 4: Distribution of water velocity in the plant-structure and the parallel pipes.

In this preliminary work, we consider the water flow through the structure under the pressure difference of $1152 \mathrm{~Pa}$ between the inlet (A) and the outlets (B) (The magnitude of the pressure difference is based on the capillary pressure of water on a tube with a diameter of $0.1 \mathrm{~mm}$-the size of the inter-yarn space in the fabric).

The output files of the Gambit software were fed into the Fluent software for the calculation of the distribution of the velocity of the liquid at different positions of the two structures.

\section{Findings of the Model}

Figure 4 presented the velocity distribution of the water along the structure obtained by a vertical dissection of the 3-D plant structure. Considering the velocity profile, it can be observed that water flow is faster in the branches than that in the main stem. The highest velocity was found at the out-let positions of the final branches. 
When the amount of water flow through the plant-structure is compared with that through the four pipes (Figure 4), the flow rate was faster through the plant-structured fabric than the total water flows through the four parallel pipes with the same total cross-sectional area. Through the plant structure, the flow rate was 0.0042 grams of water per second, but the total flow rate through the four pipes are 0.0036 grams of water. This means that for the branching structure, approximately $17 \%$ more water can pass through compared with the water flow through the four pipes under the same pressure difference during the same time. Since the model of the four uniform pipes can be regarded as a representation of the uniform small hole patterns of an interchanged plain structure, and the model of the plant structure a representation of the plant structure fabric, the difference in the flow rates through the two models provides an explanation of the differences in the liquid flow rates through the two types of fabrics. In our earlier research, we reported [6], bigger holes are observed at the backside of the fabric, and many smaller holes are noticed at the face of the branching structured fabrics, which has similarity with this model. Experiments showed that plant-structured fabric absorbs $15.4 \%$ faster as compared to the interchanged plain(see Table 4, sample no 1 and 2), which is close to the predicted results of the model.

\section{Conclusions}

Finally, it can be summarized that the superior liquid water transport properties of fabrics emulating the branching structure of plants may be a result of a combination of different mechanisms. The continuous void spaces between the yarns, which gradually reduced in diameter from the bottom layer to the top, seems to be the reason for this faster absorption. Apart from water transport through the holes, water may wick through the inter-fiber spaces in the yarn, because the same yarns are used to form the bottom layer, middle layer, and top layer in the three-layered branching structure; and bottom layer and top layer in the two-layered branching structured fabrics. As water is transported towards the top layer, water is spread into a larger number of smaller holes, before the fabric is fully saturated with water, the spreading of water in the top surface creates faster surface evaporation (because of the larger wet area for evaporation), which may result in a "cohesion-tension effect", as exists in the plants $[9,10]$, to pull the water underneath.

From the above discussion, it can be concluded that branchingstructured plant fabrics have good potential to be used as dress shirt materials and have a significant benefit as compared to existing market products. The main benefit of these fabrics is that it absorbs the liquid water faster and carries it further away as supported by the results of the vertical wicking and horizontal spreading. Such property of fabric offers extra comfort to the wearer by drying it faster. Plant structured fabrics demonstrated a significantly faster initial absorption against the similar types of single-layer woven fabrics, indicating the benefit of this novel structure. Also, all branching structured plant fabrics are breathable, airpermeability of these fabrics are much higher than regular woven fabrics. Another important aspect of the branching structured plant fabrics is that, unlike commercial knitted fabrics whose absorption property is enhanced by the chemical finishing, the superior moisture management property of the branching structured plant fabrics is based on a special structure, so it remains unaffected by repeated washing.

\section{Acknowledgment}

Funding support from the Research Grants Council of Hong Kong (PolyU 152139/20E) and PolyU AoEC Project: Wearable Technology for Personal Thermal Management (Project No: ZE1H) are gratefully acknowledged.

\section{Conflict of Interest}

Authors declare no conflict of interest.

\section{References}

1. Houshyar S, Padhye R, Troynikov O, Nayak R, Ranjan S (2015) Evaluation and improvement of thermo-physiological comfort properties of firefighters' protective clothing containing super absorbent materials. The Journal of The Textile Institute 106(12): 1394-1402.

2. Tadesse MG, Harpa R, Chen Y, Wang L, Nierstrasz V, et al. (2018) Assessing the comfort of functional fabrics for smart clothing using subjective evaluation. Journal of Industrial Textiles 48(8): 1310-1326.

3. Warner J, Wester P, Bolding A (2008) Going with the flow: river basins as the natural units for water management? Water Policy 10(S2): 121-138.

4. Schulte PJ, Brooks JR (2003) Branch junctions and the flow of water through xylem in Douglas-fir and ponderosa pine stems. J Exp Bot 54(387): 1597-1605.

5. Fan JT, Sarkar MK, Szeto YC, Tao XM (2007) Plant structured textile fabrics. Materials Letters 61(2): 561-565.

6. Sarkar MK, Fan JT, Szeto YC, Tao X (2009) Development and characterization of lightweight plant structured fabrics. Fibers and Polymers 10(3): 343-350.

7. Sarkar M, Fan J, Szeto YC, Tao X (2009) Biomimetics of Plant Structure in Textile Fabrics for the Improvement of Water Transport Properties. Textile Research Journal 79(7): 657-668.

8. Sarkar M, Fan JT, Qian X (2007) Transplanar water transport tester for fabrics. Measurement Science and Technology 18(5): 1465-1471.

9. Zaehle S (2005) Effect of height on tree hydraulic conductance incompletely compensated by xylem tapering. Functional Ecology 19(2): 359-364.

10. Du N, Fan J, Chen S, Liu Y (2008) A hydraulic-photosynthetic model based on extended HLH and its application to Coast redwood (Sequoia sempervirens). J Theor Biol 253(2): 393-400. 